\title{
Antioxidant Mechanisms of Polyphenolic Caffeic Acid Oligomers, Constituents of Salvia officinalis
}

\author{
WOLF BORS ${ }^{1}$, CHRISTA MICHEL ${ }^{1}$, KURT STETTMAIER ${ }^{1}$, YINRONG LU² and L. \\ YEAP FOO ${ }^{2}$
}

\author{
${ }^{1}$ Institut f. Strahlenbiologie, GSF Research Center, D-85764 Neuherberg, Germany \\ ${ }^{2}$ Gracefield Research Center, P.O. Box 31-310, Lower Hutt, New Zealand
}

\begin{abstract}
Caffeic acid, rosmarinic acid and oligomers of caffeic acid with multiple catechol groups are all constituents of Salvia officinalis. Their antioxidant potential was investigated with regard to their radical scavenging activity and the stability and structure of the intermediate radicals. Pulse-radiolytic studies revealed very high rate constants with hydroxyl radicals. Evidence from kinetic modeling calculations suggested an unusual complex behavior due to the presence of both $\mathrm{O}_{4}$ - and $\mathrm{O}_{3}$-semiquinones and formation and decay of a hydroxyl radical adduct at the vinyl side chain. The radical structures observed by EPR spectroscopy after autoxidation in slightly alkaline solutions were only partially identified due to their instability and generally represented dissociated $\mathrm{O}_{4}$-semiquinones. Hybrid density-functional calculations of the potential radical structures showed distinct differences between the resonance stabilization of the $\mathrm{O}_{4}-$ and $\mathrm{O}_{3}$-semiquinones of caffeic and dihydrocaffeic acids, reflected also in the considerably faster decay of the $\mathrm{O}_{3}$-semiquinone observed by pulse radiolysis. No evidence was found for dimerization reactions via C $\beta$ radicals typical for lignin biosynthesis.
\end{abstract}

Key words: Caffeic acid oligomer, catechol semiquinone, electron paramagnetic resonance, hydroxyl radical, kinetic modeling, pulse radiolysis, Salvia officinalis.

\begin{abstract}
Abbreviations: B3LYP: Becke's three parameter hybrid functional using Lee, Yang, and Parr correlation functional; DFT: density-functional theory; DPPH: 2,2-diphenyl-1-picryl hydrazyl; HRP: horseradish peroxidase; PCM: polarized continuum model.
\end{abstract}

\section{INTRODUCTION}

Salvia officinalis (sage) dried leaves are commonly used as a culinary spice for flavoring and seasoning. The name Salvia comes from the Latin meaning 'to heal' and points to the popularity of this plant in traditional medicine $(1,2)$. Sage is reputed to be one of the richest sources of potent antioxidants (3-6), being rosmarinic acid, carnosic acid and their derivatives the bestknown examples $(4,7)$. Recent studies showed that various Salvia species including Salvia officinalis $(6,8-10)$ contain a surprisingly high number of diverse catechol compounds, most comprising oligomers of caffeic acid. The caffeic acid oligomers have been shown to be very effective scavengers of 2,2-diphenyl-1-picryl hydrazyl (DPPH) and superoxide anion $(10,11)$. For a more detailed study of their antioxidant mechanisms, we selected five minor constituents of Salvia officinalis, all with multiple catechol moieties (see Scheme I). Pulse radiolysis (12-14) was employed to study the radical scavenging effectivity and stability of the semiquinone structures. EPR spectroscopy (15) was used to identify likely radical target sites of the individual catechol structures and hybrid density-functional theory (DFT) calculation $(16,17)$ was used to confirm the experimentally obtained isotropic coupling constants and to assign the respective hydrogen atoms. 


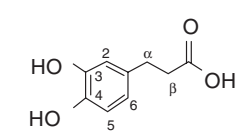

dihydrocaffeic acid (\#1a)
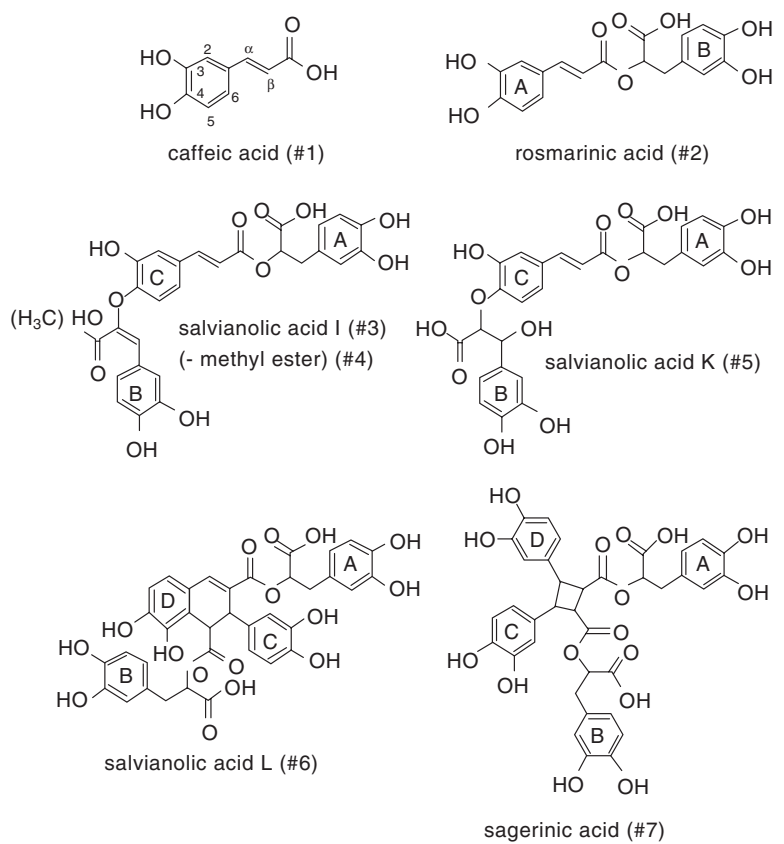

Scheme I. Structures of sage phenolic acids (caffeic acid and oligomers).

\section{MATERIALS AND METHODS}

Caffeic acid (3,4-dihydroxycinnamic acid) and its oligomers were isolated from Salvia officinalis (8-10); in addition, caffeic acid and dihydrocaffeic acid (3,4dihydroxydihydrocinnamic acid) were purchased from Fluka (Taufkirchen, Germany) and rosmarinic acid from ICN Biochemicals (Eschwege, Germany). Horseradish peroxidase (type VI), hydrogen peroxide (perhydrol), and sodium azide were also obtained from Fluka (Taufkirchen, Germany).

Pulse-radiolytic experiments were carried out with hydroxyl $(\bullet \mathrm{OH})$ radicals as electrophilic species in slightly alkaline solutions as described earlier (12-14). For this purpose, solutions were prepared with Milli-Q water and saturated with $\mathrm{N}_{2} \mathrm{O}$. The transient kinetics were evaluated both by linear regression analyses of pseudo-first and second order reactions and, owing to the deviations from these simple first- or second-order kinetics, by kinetic modeling of probable sequences of reactions $(12,18)$.
EPR spectra were recorded after oxidation of the substances with horseradish peroxidase/ hydrogen peroxide $\left(\mathrm{HRP} / \mathrm{H}_{2} \mathrm{O}_{2}\right)$ in alkaline solution $(\mathrm{pH}$ 8.79.8), using a Bruker ESP-300 instrument, X-band, modulation amplitude 0.4 Gauss, gain $5 \times 10^{3}$, microwave power $20 \mathrm{~mW}$, and scan speed of 0.6 Gauss/second (15).

Calculations based on hybrid densityfunctional theory (DFT) at the B3LYP level of theory were carried out with Gaussian98 (19). Three-dimensional structures were geometrically optimized with ChemOffice MOPAC restricted Hartree-Fock (CambridgeSoft) and the Z-matrix imported into the Gaussian program. Using the model compound caffeic acid and its possible radical structures, various basis sets were assayed for their correlation with the experimental data, taking into consideration the solvent water using the polarized continuum model (PCM). The best correlations between experimentally and theoretically derived coupling constants were obtained with the basis sets $6-311 G^{*}$ and $6-311 \mathrm{G}^{* *}$.

\section{RESULTS}

\section{Pulse radiolysis}

Despite the fact that all compounds contain at least one and up to 4 catechol structures within the molecule, as seen in Figure 1, the transient spectra depict quite considerable differences. The figure is divided into two sections to highlight the difference between the first four substances with apparent bleaching of the parent compounds and that of compounds \#5 and \#7, which do so only minimally.

Comparing the literature values for caffeic acid, the only compound studied before, they showed a good agreement with the value we obtained with linear regression analysis: $7.4 \times 10^{9}$ at $385 \mathrm{~nm}$ vs. $5.5 \times 10^{9}$ at $400 \mathrm{~nm}$ (20) or $7.4 \times 10^{9}$ at $470 \mathrm{~nm}$ (21), all dimensions $\mathrm{M}^{-1} \mathrm{~s}^{-1}$. Yet, almost consistently we encountered biphasic build-up and decay kinetics as deviations from simple pseudo-first order build-up and secondorder decay, and therefore resorted to a kinetic modeling approach $(12,18)$. As listed in Table I, optimal fits of the 

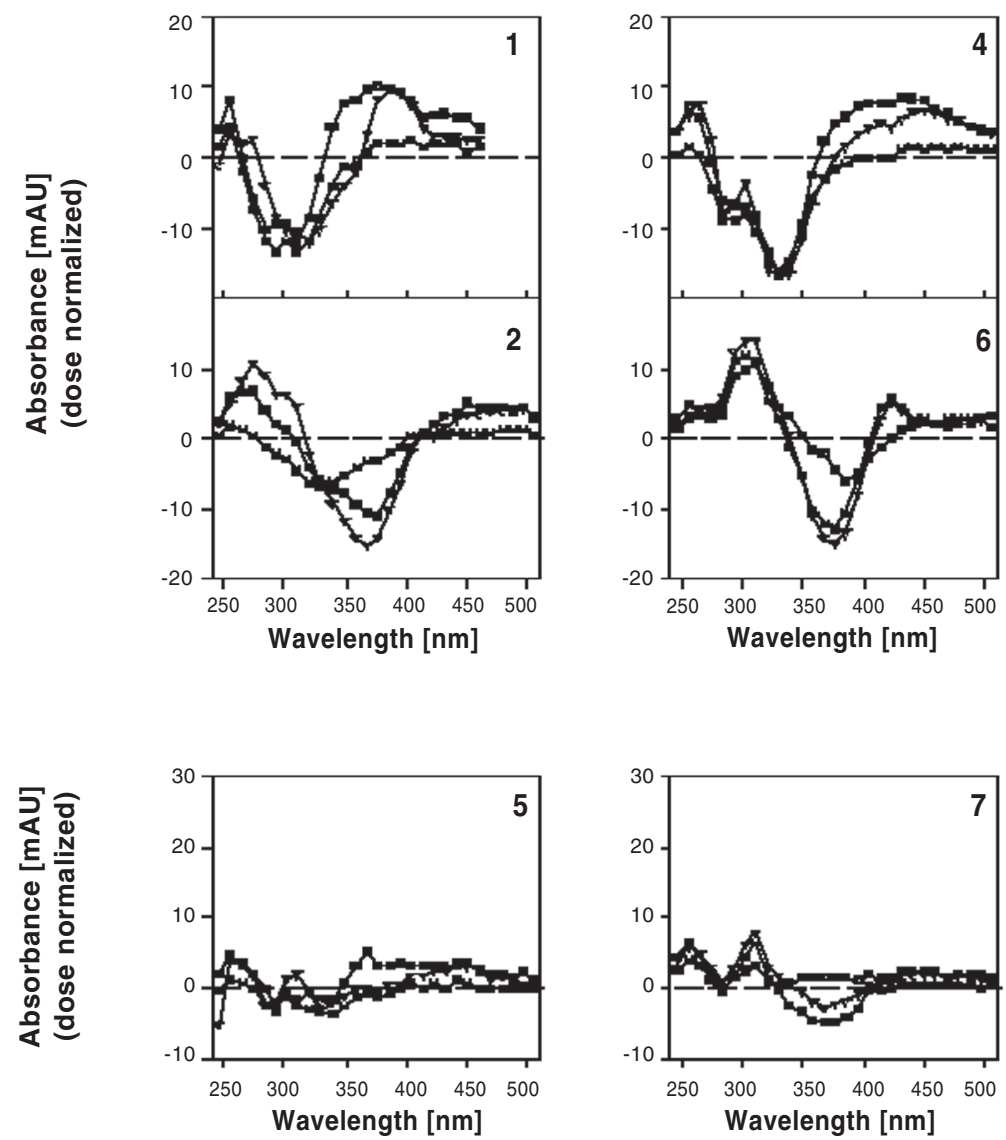

Figure 1. Pulse-radiolytic transient spectra of caffeic acid oligomer semiquinones generated with hydroxyl radicals dose-normalized. All initial transient spectra - solid circles - observed at $5 \mu \mathrm{s}$ after the pulse; solid triangles and diamonds depict intermediate observation times varying according to the optical changes; solid squares, depict the final observation period.

Figure 1a: 1 - caffeic acid: $44.4 \mu$ moles, $\mathrm{pH} 8.5 ; 2$ - rosmarinic acid: $47.8 \mu$ moles, $\mathrm{pH} 8.4 ; 3$ salvianolic acid I: $36.3 \mu$ moles, $\mathrm{pH}$ 8.7-8.8; 4 - salvianolic acid I methyl ester: $35.0 \mu$ moles, $\mathrm{pH}$ 8.6-8.7; 6 - salvianolic acid L: 43.0 moles, pH 8.7.

Figure 1b: 5 - salvianolic acid K: $43.6 \mu$ moles, pH 8.5; 7 - sagerinic acid: 32.8 moles, pH 8.5.

TABLE I

Results of kinetic modeling in hydroxyl radical system

\begin{tabular}{lccccccc}
\hline \multicolumn{1}{c}{ Substance } & $\lambda$ & $\begin{array}{c}\mathrm{k}_{1 \mathrm{p}} \\
\left(\mathrm{x} 10^{9} \mathrm{M}^{-1} \mathrm{~s}^{-1}\right)\end{array}$ & $\begin{array}{c}\mathrm{k}_{2 \mathrm{~m}} \\
\left(\times 10^{9} \mathrm{M}^{-1} \mathrm{~s}^{-1}\right)\end{array}$ & $\begin{array}{c}2 \mathrm{k}_{3 \mathrm{p}} \\
\left(\times 10^{6} \mathrm{M}^{-1} \mathrm{~s}^{-1}\right)\end{array}$ & $\begin{array}{c}2 \mathrm{k}_{4 \mathrm{~m}} \\
\left(\times 10^{8} \mathrm{M}^{-1} \mathrm{~s}^{-1}\right)\end{array}$ & $\begin{array}{c}\mathrm{k}_{5} \\
\left(\times 10^{5} \mathrm{M}^{-1} \mathrm{~s}^{-1}\right)\end{array}$ & $\mathrm{n}$ \\
\hline caffeic acid (\#1) & 385 & 10.2 & 4.05 & 11.8 & 2.95 & - & 9 \\
rosmarinic acid (\#2) & 455 & 3.85 & 6.05 & 17.9 & 12.4 & - & 9 \\
salvianolic acid I (\#3) & 440 & 2.85 & 5.85 & 6.40 & 11.8 & - & 9 \\
salvianolic acid I ester (\#4) & 440 & 8.65 & 3.05 & 2.95 & 17.2 & - & 8 \\
salvianolic acid K (\#5) & 450 & 3.45 & 4.50 & - & 3.05 & 5.60 & 6 \\
sagerinic acid (\#7) & 450 & 2.50 & 6.90 & 1.40 & 5.70 & - & 7 \\
\hline
\end{tabular}


experimental digitized data points with the theoretical curves were achieved by the model where we assumed synchronous formation of ortho-semiquinones with the principal radical site in either $\mathrm{O}_{3}-(3-\mathrm{PhO} \bullet)$ or $\mathrm{O}_{4^{-}}(4-\mathrm{PhO} \bullet)$ position (22) - reactions [1, 2]:
[1] $\bullet \mathrm{OH}+\mathrm{PhO}-$
$\rightarrow \quad 4-\mathrm{PhO} \bullet+\mathrm{H}_{2} \mathrm{O}$
[2] $\bullet \mathrm{OH}+\mathrm{PhO}-$
$\rightarrow \quad 3-\mathrm{PhO} \bullet+\mathrm{H}_{2} \mathrm{O}$
[3] $4-\mathrm{PhO} \bullet+4-\mathrm{PhO} \bullet \rightarrow \mathrm{PhO}-+\mathrm{Ph}=\mathrm{O}$
[4] 3-PhO $+3-\mathrm{PhO} \bullet \rightarrow$ PhO- $+\mathrm{Ph}=\mathrm{O}$
[5] $\mathrm{Ph}=\mathrm{O}$
$\rightarrow$ product

Both semiquinone mesomers are assumed to decay by second order to the same corresponding quinones and parent catechols (reactions [3, 4]), albeit at quite different rate constants with the $\mathrm{O}_{3}$ semiquinone being far more unstable. Accounting for the bimolecular recombination of the $\cdot \mathrm{OH}$ radicals was required because of the nonstoichiometric scavenging at the low concentrations of the substrates. Modified kinetic schemes, taking into account the addition of $\bullet \mathrm{OH}$ radicals either at the aromatic ring (23) or at the vinyl side chain (24), gave optimal results only in two cases (data not shown).

\section{EPR spectroscopy}

Generating radicals in the EPR cavity by oxidation with $\mathrm{HRP} / \mathrm{H}_{2} \mathrm{O}_{2}$ in alkaline solutions (15) resulted in signals of the principal radicals which should all represent the ortho-semiquinone structures (Fig 2). While there is some apparent similarity between the spectra for \#1, \#2 and \#7, on the one hand, and \#6, \#5 on the other hand, it has to be emphasized that this similarity is only superficial and does not allow to deduct analogous coupling constants. Furthermore, basically all EPR spectra are more or less unstable resulting in overlapping spectra which prevented quantitative evaluation for substances \#4, \#6, and \#7. Dihydrocaffeic acid (\#1a) was included only for the EPR (and DFT) studies in view of the presence of both saturated and unsaturated side chains in compounds \#2-5.
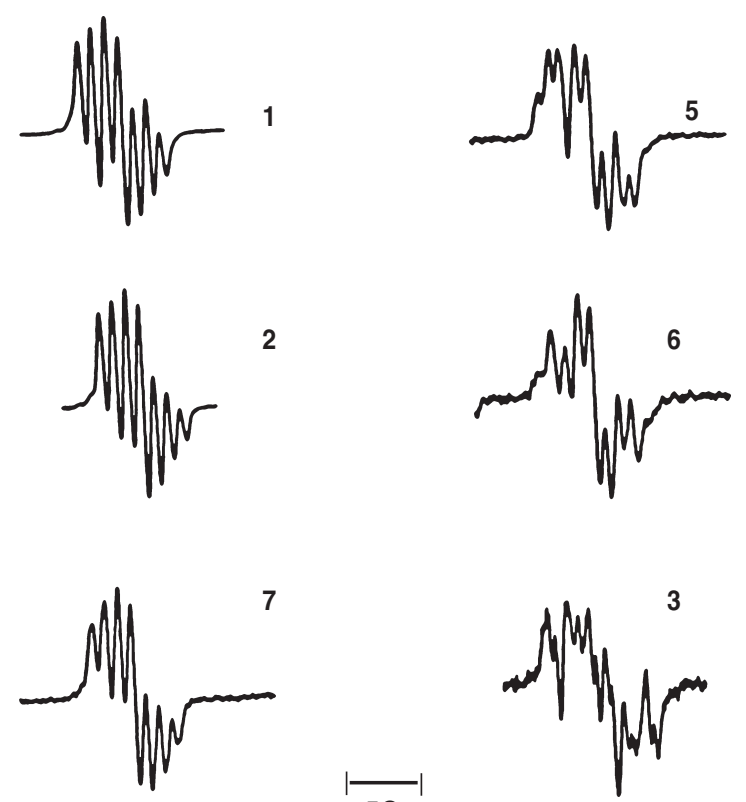

7

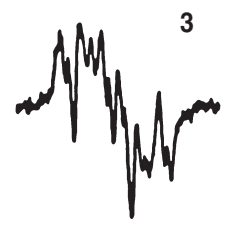

Figure 2. EPR spectra of caffeic acid oligomer radicals horseradish peroxidase, $10 \mu \mathrm{L}$ of stock solution, $7 \mu$ moles, in $1 \mathrm{~mL}$ substrate solution, the reaction was started by adding $40 \mu \mathrm{L}$ hydrogen peroxide of a stock solution, 87 mmoles;

1 - caffeic acid, 2.67 mmoles, pH 9.8; 2 rosmarinic acid, 1.34 mmoles, $\mathrm{pH} 9.5 ; 6$ salvianolic acid L, 0.7 mmoles, $\mathrm{pH} 8.7 ; 7$ sagerinic acid, 0.69 mmoles, $\mathrm{pH} 8.9$; 3, salvianolic acid I, 0.89 mmoles, $\mathrm{pH} 9.5$; 5, salvianolic acid K, 0.92 mmoles, pH 9.2.

In Figure 3, the EPR spectra of caffeic (a) and dihydrocaffeic acids (b) at $\mathrm{pH} 9.6$ and at different times are compared in the abscence and presence of zinc acetate. In the absence of $\mathrm{Zn}^{2+}$ (left panels) only the $\mathrm{O}_{4}$-semiquinone radical anion exists. In the presence of $\mathrm{Zn}^{2+}$ the so-called 'spinstabilization' effect $(25,26)$ is apparent only for caffeic acid, reflected in the considerable change of the peak height ratios when comparing the initial and the 50 seconds spectra. Since all spectra decay over time, this 'spin stabilization' is actually a misnomer and should better be phrased 'spin enhancement' since the formation of the $\mathrm{Zn}^{2+}$ complexes causes a considerable increase of the signals (factor of two for caffeic acid and five for 

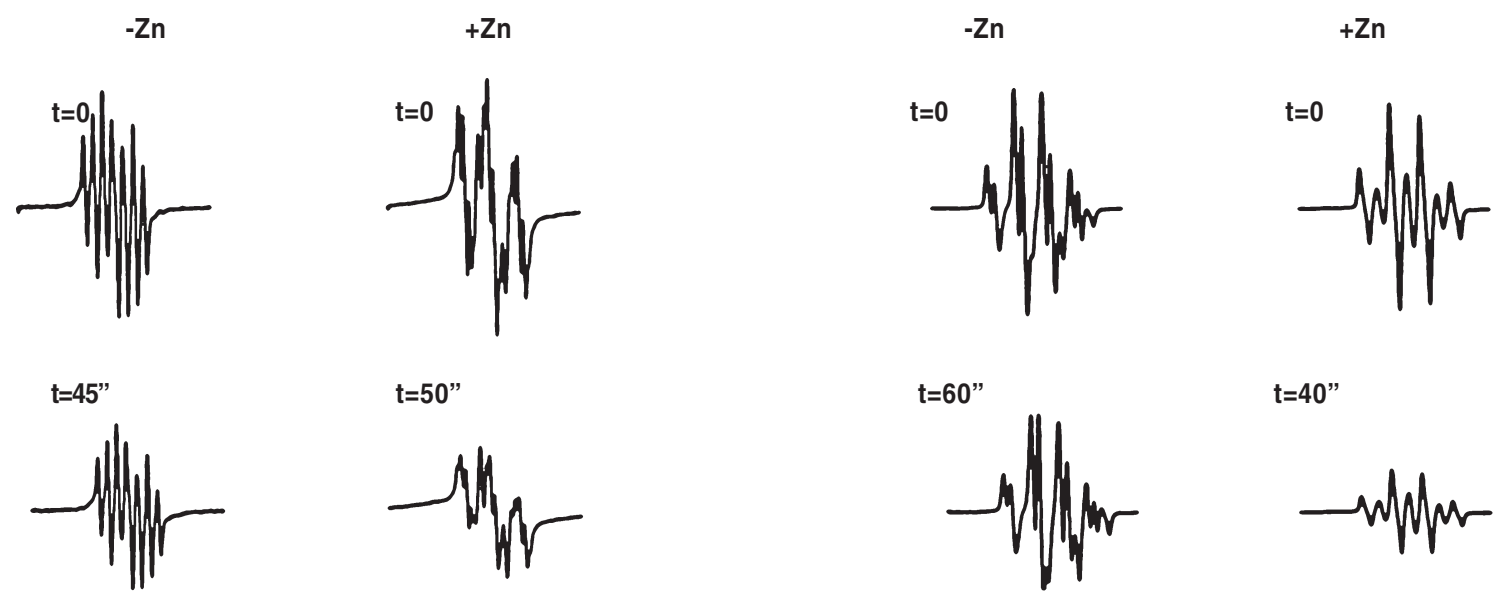

$t=40 "$

$t=195 "$

$t=150 "$

$t=165 ”$

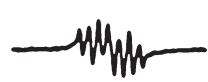

$t=145^{\prime \prime}$

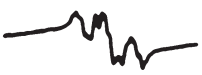

A
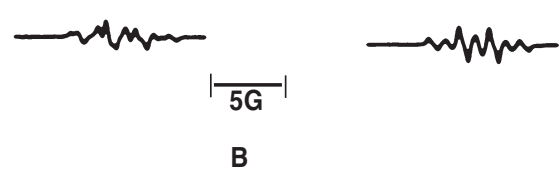

Figure 3. EPR spectra of caffeic and dihydrocaffeic acid radicals anions in the absence and presence of zinc acetate. Horseradish peroxidase, $10 \mu \mathrm{L}$ of stock solution, $7 \mu$ moles, in $1 \mathrm{~mL}$ substrate solution, $\mathrm{pH} 9.6$, the reaction was started by adding $40 \mu \mathrm{L}$ hydrogen peroxide of a stock solution, 87 mmoles; times given are delay times after the first measurement.

(a) caffeic acid (5.9 mmoles), left panel without $\mathrm{Zn}^{2+}$, arbitrary ordinate scale \pm 1700 ; right panel with $\mathrm{Zn}^{2+}$ (46 mmoles), arbitray ordinate scale \pm 3000 ;

(b) dihydrocaffeic acid (6.8 mmoles), left panel without $\mathrm{Zn}^{2+}$, arbitrary ordinate scale \pm 3000 ; right panel with $\mathrm{Zn}^{2+}$ (46 mmoles), arbitray ordinate scale \pm 15000 .

dihydrocaffeic acid, arbitrary ordinate scale). In any case, the $\mathrm{Zn}^{2+}$-stabilized spectra of caffeic acid thus verify the formation of both $\mathrm{O}_{3}$ - and $\mathrm{O}_{4}$-semiquinones in analogy to the studies of Rettori et al. (22) and the kinetic modeling calculations (see above).

In Table II, we compared experimentally obtained coupling constants both from the literature (27-31) and from our own studies (14) for caffeic and dihydrocaffeic acids with theoretical values obtained from density-functional calculations. The calculations also resulted in isotropic coupling constants for radical species (i.e. the $\mathrm{O}_{3}$-semiquinones of caffeic acid and dihydrocaffeic acid, the $\bullet \mathrm{OH}$ adduct radicals of \#1) which were too unstable to be observable with EPR spectroscopy, yet yielded quite different data indicative of distinct radical structures. What needs to be emphasized is the fact that due to the large size of the molecules of caffeic acid oligomers, DFT calculation of their radicals was limited to smaller model structures, representing the most likely radical sites $(14,17)$. Table III lists the experimentally derived isotropic coupling constants for the caffeic acid oligomers for which an evaluation was possible. They are compared with those theoretically obtained values, which most closely correspond to the experiments and whose structures are shown in the lower part of the table.

An unexpected result of the DFT calculations was the fact that for the caffeic acid dianion radical, eight different mesomeric structures (depicted in the first 


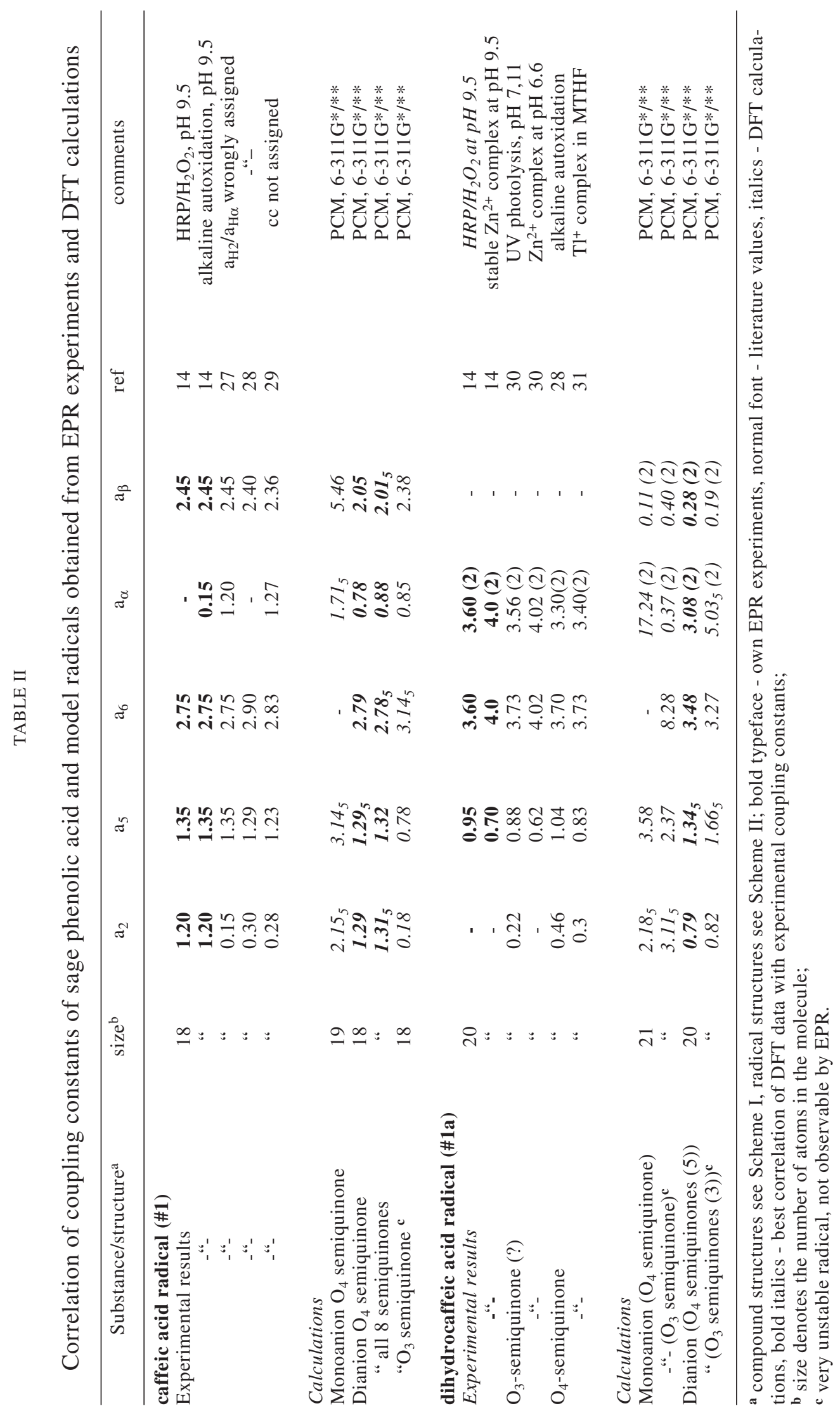


TABLE III

Isotropic coupling constants of semiquinones of caffeic acid oligomers from experiments and DFT calculations

\begin{tabular}{|c|c|c|c|c|c|c|c|c|}
\hline Substance $^{\mathrm{a}}$ & $\operatorname{size}^{b}$ & $\mathrm{a}_{\mathrm{H} 2}$ & $\mathrm{a}_{\mathrm{H} 5}$ & $\mathrm{a}_{\mathrm{H} 6}$ & $\mathrm{a}_{\mathrm{H} \alpha}$ & $a_{H \beta}$ & $\mathrm{A}_{\mathrm{H} \gamma}$ & comment \\
\hline \multicolumn{9}{|l|}{ Rosmarinic acid } \\
\hline Experimental & 39 & 2.58 & 1.26 & - & - & 3.85 & - & $\mathrm{HRP} / \mathrm{H}_{2} \mathrm{O}_{2}$ \\
\hline Calculated (1) & “ & 2.50 & 1.27 & 2.14 & 0.67 & 2.08 & 0.26 & PCM 6-311G* \\
\hline \multicolumn{9}{|c|}{ Salvianolic acid I } \\
\hline Experimental & 40 & 2.0 & 3.8 & 0.8 & 4.0 & - & - & $\mathrm{HRP} / \mathrm{H}_{2} \mathrm{O}_{2}$ \\
\hline Calculated (2) & “ & 1.89 & 3.84 & 0.35 & $4.06(2)$ & 0.41 & - & PCM 6-311G* \\
\hline \multicolumn{9}{|c|}{$\underline{\text { Salvianolic acid K }}$} \\
\hline Experimental & 40 & 3.9 & 1.8 & 8.1 & - & 1.8 & - & $\mathrm{HRP} / \mathrm{H}_{2} \mathrm{O}_{2}$ \\
\hline Calculated (3) & “ & 4.0 & 1.58 & 9.57 & 0.69 & 0.98 & 3.27 & PCM 6-311G* \\
\hline
\end{tabular}

${ }^{\text {a }}$ compound structures see Scheme I

b size denotes the number of atoms in the molecule.<smiles>COc1ccc(/C=C/C(=O)OC(Cc2ccc(O)c(O)c2)C(=O)[O-])cc1OC</smiles><smiles>O=C(/C=C/c1ccc(O)c(O)c1)OC(Cc1ccc(O)c(O)c1)C(=O)[O-]</smiles><smiles>COc1cc(/C=C/C(=O)O)ccc1OC(C(=O)O)C(O)c1ccc(O)c(O)c1</smiles>

two lines in Scheme II) have basically the same coupling constants as the $\mathrm{O}_{4}$ semiquinone itself and only the $\mathrm{O}_{3}$ semiquinone deviates. In the case of the dihydrocaffeic acid dianion radical, as shown in the lower two lines of the scheme, four mesomeric structures for the $\mathrm{O}_{4}$ semiquinone stand opposed to three for the $\mathrm{O}_{3}$-semiquinone.
DISCUSSION

Reactivity with $\bullet \mathrm{OH}$ radicals generated during pulse-radiolytic experiments demonstrated the highly effective radicalscavenging potential of the caffeic acid oligomers, with rate constants at diffusioncontrolled limits. The complex and diverse kinetic behavior, as revealed by biphasic 

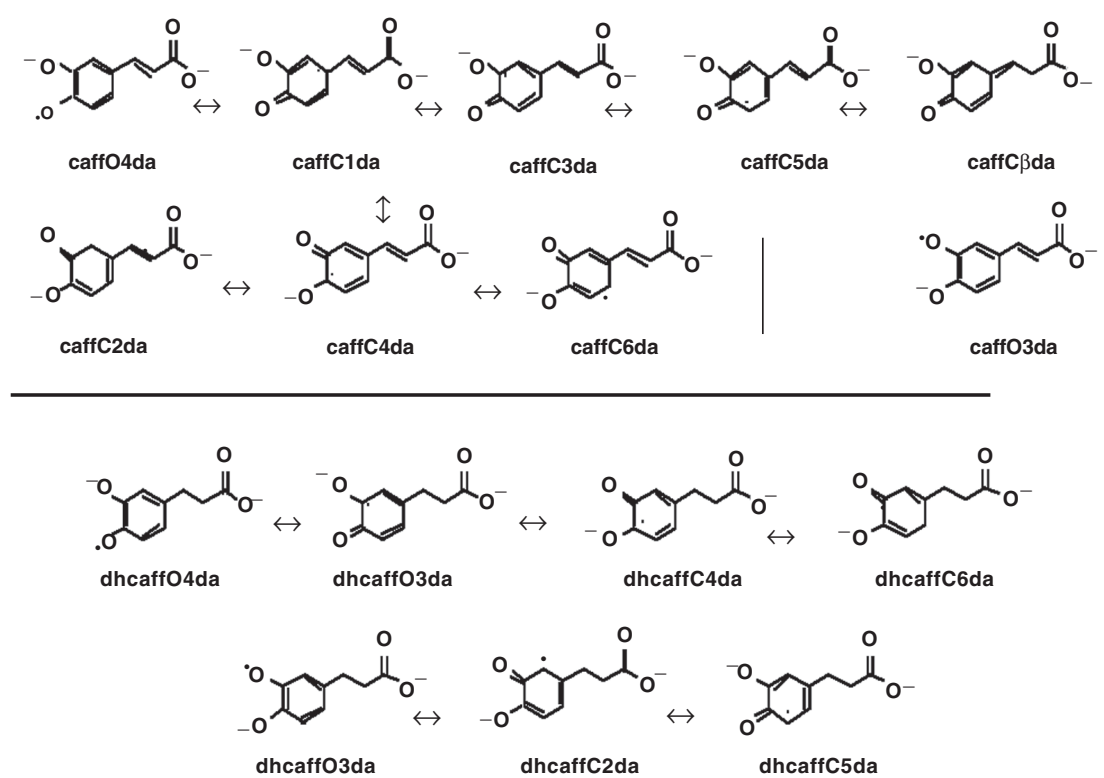

Scheme II. Relevant mesomeric and isomeric structures of caffeic acid and dihydrocaffeic acid radicals used for DFT calculations.

build-up and decay of individual transient absorptions, could optimally be modeled by the kinetic scheme presented above. From the rate constants listed in Table II, it is apparent that the ratio of reactions [1] and [2] governs both the initial build-up as well as the mono- or biphasic decay. While in general build-up kinetics reflect pseudofirst order attack of the primary radicals, decay occurs by second order disproportionation of the semiquinones to the same parent compound and respective quinone. Monophasic behavior occurs whenever one reaction dominates strongly over the others. Potential dimerization (24, $32,33)$ instead of disproportionation - with the focal point being the 'CaffC $\beta$ da' mesomeric structure (top right in Scheme II) - would not be apparent in the kinetic model as both are second-order processes. As shown in Table III, the DFT calculations support the distinction between the different stabilities of the mesomers, with a far superior electron delocalization (hence resonance stabilization of the radical) of the respective $\mathrm{O}_{4}$-semiquinones.

With regard to the EPR spectra, we mainly observed the same $4-\mathrm{PhO} \bullet$ species at least part-time, since we obtained the best agreement of experimental, literature values and theoretical coupling constants for caffeic acid $(27,28)$ and dihydrocaffeic acid $\mathrm{O}_{4}$-semiquinone dianions $(28,30,31)$, including all possible mesomeric structures. In view of the unreflected depiction of both the $\mathrm{O}_{4^{-}}(28,31)$ and $\mathrm{O}_{3}$-semiquinones (30) as probable radical structures, as well as the obviously wrongly assigned $\mathrm{a}_{\mathrm{H} 2} / \mathrm{a}_{\mathrm{H} \alpha}$ for the caffeic acid radical $(26,28)$, the theoretical studies could thus be used as final arbiters of questionable radical structures.

Following the same approach as Cadenas and coworkers (22), the spin-stabilization studies using an excess of zinc acetate (25, $26,30)$ in moderately alkaline solutions $(\mathrm{pH}$ 9.6-9.8) clearly reveal the presence of more than one radical species, whereas in the absence of $\mathrm{Zn}^{2+}$ only one radical is seen. The results thus support our assumption of the simultaneous formation of both $\mathrm{O}_{3}$ - and $\mathrm{O}_{4}$-semiquinones in the kinetic modeling calculations, where the $\mathrm{O}_{3}$-semiquinone is too unstable to be seen in the absence of the bivalent ion, but becomes stabilized in its presence.

Consistent with earlier observations (16, 17), we always achieved better correlations between experimental and theoretical calculations for the coupling constants of the aromatic as compared to the side-chain 
hydrogen atoms. In fact, comparing the theoretical coupling constants of the neutral and dissociated catechol radicals (the carboxyl group is always considered dissociated), the participation of the excess electron from the phenolate group obviously enhances the overall resonance stabilization (data not shown). Since application of this theoretical approach for more complex structures is still in its infancy, the only comparable studies were carried out for the calculations of the spin densities of three undissociated semiquinone structures of caffeic acid (34) and calculations of bond-dissociation energies of phenolic protons $(35,36)$.

\section{CONCLUSIONS}

Using pulse radiolysis, EPR spectroscopy and the ancillary theoretical approaches of kinetic modeling and hybrid densityfunctional theory calculations, over the years we have studied the antioxidant mechanisms of various natural polyphenolic compounds. Based upon these observations and confirming evidence from the literature, we can distinguish between three different types of mechanisms:

- flavonoids proper, especially 3-hydroxy flavonols, have the preferred site of attack in the catechol structure of the Bring, with the initially formed semiquinone stabilized by the 2,3-double bond $(37,38)$; the quinones and quinone methides, formed after disproportionation of the semiquinones, are potential prooxidants either due to futile redox cycling or nucleophilic attack at macromolecules $(39,40)$;

- proanthocyanidins (condensed tannins) as well as gallo- and ellagitannins (hydrolyzable tannins) likewise form semiquinones after initial radical attack and quinones/quinone methides by subsequent disproportionation; however, in this case, the quinones may combine with the parent catechol structures by phenolic coupling, thereby doubling the size of the molecule; this oligomerization in effect causes an enhancement of the antioxidant potential of these compounds $(13,41)$;

- multiple catechol structures in the caffeic acid oligomers are again the major target sites during their antioxidant function; in this case, however, complex kinetics due to parallel attack at various sites (simultaneous formation of both a $\mathrm{O}_{3}$ and $\mathrm{O}_{4}$-semiquinone, attack at aliphatic vinyl side chains) obscure the overall picture (14). While the eventually formed quinones are stable within the pulse-radiolytic time frame, evidence from the literature suggests that slow dimerization reactions occur via various mesomeric semiquinone structures (24, $32,33)$.

An interesting aspect of these mechanisms is the close similarity with potential biosynthetic pathways. Both types of tannins form oligomers in chemical syntheses with structures resembling natural compounds, yet the underlying enzymatic reactions are still unknown (4244). With regard to the dimerisation of caffeic acid $(24,32,33)$, similar radicalinduced reactions seem to take place during the biosynthesis of lignins (45-47).

\section{REFERENCES}

1. KASIMU R, TANAKA K, TEZUKA Y, GONG ZN, LI JX, BASNET P, NAMBA T, KADOTA S (1998) Comparative study of seventeen Salvia plants: Aldose reductase inhibitory activity of water and $\mathrm{MeOH}$ extracts and liquid chromatography mass spectrometry (LC-MS) analysis of water extracts. Chem Pharm Bull 46: 500-504

2. LI LN (1998) Biologically active components from traditional Chinese medicines. Pure Appl Chem. 70: 547-554

3. NAKATANI N (1994) Chemistry of antioxidants from labiatae herbs. in: Food Phytochemicals for Cancer Prevention. II.Teas, Spices, and Herbs (Ho, C.T., Osawa, T., Huang, M.T., Rosen, R.T., eds., Am Chem Soc, Washington, DC), ACS Sympos Ser 547: 144-153

4. CUVELIER ME, RICHARD H, BERSET C (1996) Antioxidative activity and phenolic composition of pilot-plant and commercial extracts of sage and rosemary. J Am Oil Chem Soc 73: 645-652

5. MADSEN HL, BERTELSEN G, SKIBSTED LH (1997) Antioxidative activity of spices and spice extracts. in: Spices (Risch, S.J., Ho, C.T., eds., ACS Press, Washington DC), ACS Sympos Ser 660: 176-187

6. LU Y, FOO LY, WONG H (2002) Polyphenolics of Salvia - a review. Phytochemistry 59: 117-140 
7. WANG MF, LI JG, RANGARAJAN M, SHAO Y, LAVOIE E J, HUANG TC, HO CT (1998) Antioxidative phenolic compounds from sage (Salvia officinalis). J Agric Food Chem 46: 4869-4873

8. LU Y, FOO LY (1999) Rosmarinic acid derivatives from Salvia officinalis. Phytochemistry 51: 91-94

9. LU Y, FOO LY, WONG H (1999) Sagecoumarin, a novel caffeic acid trimer from Salvia officinalis. Phytochemistry 52: 1149-1152

10. LU Y, FOO LY (2001) Salvianolic acid L. A potent antioxidant from Salvia officinalis. Tetrahedron Lett 42: 8223-8225

11. LU Y, FOO LY (2001) Antioxidant activity of polyphenols from sage (Salvia officinalis). Food Chem 75: 197-202

12. BORS W, MICHEL C (1999) Antioxidant capacity of flavanols and gallate esters: Pulse radiolysis studies. Free Radical Biol Med 27: 1413-1426

13. BORS W, FOO LY, HERTKORN N, MICHEL C, STETTMAIER K (2001) Chemical studies of proanthocyanidins and hydrolyzable tannins. Antiox Redox Signal 3: 995-1008

14. BORS W, MICHEL C, STETTMAIER K, LU YR, FOO LY (2002) Pulse radiolysis, EPR spectroscopy and theoretical calculations of caffeic acid oligomer radicals. Biochim Biophys Acta, 1620: 97-107.

15. BORS W, MICHEL C, STETTMAIER K (2000) Electron paramagnetic resonance studies of radical species of proanthocyanidins and gallate esters. Arch Biochem Biophys 374: 347-355

16. BORS W, KAZAZIC SP, MICHEL C, KORTENSKA VD, STETTMAIER K and KLASINC L (2002) Methoxyphenols - antioxidant principles in food plants and spices: pulse radiolysis, EPR spectroscopy and DFT calculations. Int J Quant Chem 90: 969-979

17. BORS W, MICHEL C, STETTMAIER K, KAZAZIC SP and KLASINC L (2002) DFT calculations of isotropic coupling constants of phenoxyl and aroxyl radicals. Croat. Chem. Acta., 75: 957-964

18. BORS W, MICHEL C, SCHIKORA S (1995) Interaction of flavonoids with ascorbate and determination of their univalent redox potentials: A pulse radiolysis study. Free Radical Biol Med 19: 4552

19. FRISCH MJ, TRUCKS GW, SCHLEGEL HB, SCUSERIA GE, ROBB MA, CHEESEMAN JR, ZAKRZEWSKI VG, MONTGOMERY JA, STRATMANN RE, BURANT JC, DAPPRICH S, MILLAM JM, DANIELS AD, KUDIN KN, STRAIN MC, FARKAS O, TOMASI J, BARONE V, COSSI M, CAMMI R, MENNUCCI B, POMELLI C, ADAMO C, CLIFFORD S, OCHTERSKI J, PETERSSON GA, AYALA PY, CUI Q, MOROKUMA K, MALICK DK, RABUCK AD, RAGHAVACHARI K, FORESMAN JB, CIOSLOWSKI J, ORTIZ JV, BABOUL AG, STEFANOV BB, LIU G, LIASHENKO A, PISKORZ P, KOMAROMI I, GOMPERTS R, MARTIN RL, FOX D J, KEITH T, AL-LAHAM M A, PENG CY, NANAYAKKARA A, GONZÁLEZ C, CHALLACOMBE M, GILL P M W, JOHNSON B, CHEN W, WONG M W, ANDRÉS JL, GONZÁLEZ C, HEAD-GORDON M, REPLOGLE ES, POPLE JA (1998) Gaussian 98, Revision A.7, Gaussian, Inc., Pittsburgh, PA.

20. LI X F, CAI ZL, KATSUMURA Y, WU GZ, MUROYA Y (2001) Reactions of reducing and oxidizing radicals with caffeic acid: a pulse radiolysis and theoretical study. Radiat Phys Chem 60: 345-350

21. WANG WF, LUO J, YAO SD, LIAN ZR, ZHANG JS, LIN NY, FANG RY, HU TX (1993) Interaction of phenolic antioxidants and hydroxyl radicals. Radiat Phys Chem 42: 985-987

22. RETTORI D, TANG Y, DIAS LC, CADENAS E (2002) Pathways of dopamine oxidation mediated by nitric oxide. Free Radical Biol Med 33: 685-690

23. BORS W, MICHEL C (1997) Lipoate redox function in chemical systems. in: Lipoic Acid in Health and Dis ease, Fuchs J, Packer L, Zimmer G, eds., New York, Marcel Dekker, pp. 33-46

24. HAPIOT P, NEUDECK A, PINSON J, FULCRAND H, NETA P, ROLANDO C (1996) Oxidation of caffeic acid and related hydroxycinnamic acids. J Electroanal Chem 405: 169-176

25. EATON DR (1964) Complexing of metal ions with semiquinones. An ESR study. Inorg Chem 3: 12681271

26. KALYANARAMAN B (1990) Characterization of osemiquinone radicals in biological systems. Meth Enzymol 186: 333-342

27. DIXON WT, MOGHIMI M, MURPHY D (1975) Electron spin resonance study of the stereochemistry of radicals related to cinnamic acid. JCS, Perkin II: 1189-1191

28. PEDERSEN JA, OLLGAARD B (1982) Phenolic acids in the genus Lycopodium. Biochem System Ecol 10: 3-9

29. PEDERSEN JA (2000) Distribution and taxonomic implications of some phenolics in the family Lamiaceae determined by ESR spectroscopy. Biochem System Ecol 28: 229-253

30. FELIX CC, SEALY RC (1981) Photolysis of melanin precursors: Formation of semiquinone radicals and their complexation with diamagnetic metal ions. Photochem Photobiol 34: 423-425

31. STEGMANN HB, DAO-BA H, STOLZE K, SCHEFFLER K (1985) ESR- und ENDORUntersuchungen an Catecholaminen und deren Metaboliten als paramagnetische Thallium-Komplexe. Z. Anal Chem 322: 430-436

32. CILliERS JJL, SINGLETON VL (1991) Characterization of the products of nonenzymic autoxidative phenolic reactions in a caffeic acid model system. J Agric Food Chem 39: 1298-1303

33. HOTTA H, SAKAMOTO H, NAGANO S, OSAKAI T, TSUJINO Y (2001) Unusually large numbers of electrons for the oxidation of polyphenolic antioxidants. Biochim Biophys Acta 1526: 159-167

34. BAKALBASSIS EG, CHATZOPOULOU A, MELISSAS VS, TSIMIDOU $M$, TSOLAKI M, VAFIADIS A (2001) Ab initio and density functional theory studies for the explanation of the antioxidant activity of certain phenolic acids. Lipids 36: 181-190

35. ZHANG HY, SUN YM, CHEN DZ (2001) O-H bond dissociation energies of phenolic compounds are determined by field/inductive effect or resonance effect? A DFT study and its implication. Quant Struct Act Relat 20: 148-152

36. ZHANG HY, SUN YM, WANG XL (2002) Electronic effects on $\mathrm{O}-\mathrm{H}$ proton dissociation energies of phenolic cation radicals: A DFT study. J Org Chem 67: 2709-2712

37. BORS W, HELLER W, MICHEL C, SARAN M (1990) Flavonoids as antioxidants: determination of radical scavenging efficiencies. Meth Enzymol 186: 343-354

38. BORS W, MICHEL C, STETTMAIER K (2001) Structure-activity relationships governing antioxidant capacities of plant polyphenols. Meth Enzymol 335: 166-180

39. AWAD HM, BOERSMA MG, BOEREN S, BLADEREN PJ VAN, VERVOORT J, RIETJENS IMCM (2001) Structure-activity study on the quinone/ quinone methide chemistry of flavonoids. Chem Res Toxicol 14: 398-408 
40. RIETJENS IMCM, BOERSMA MG, HAAN L DE, SPENKELINK B, AWAD HM, CNUBBEN NHP, ZANDEN JJ VAN, WOUDE H VAN DER, ALINK GM, KOEMAN JH (2002) The pro-oxidant chemistry of the natural antioxidants vitamin $\mathrm{C}$, vitamin $\mathrm{E}$, carotenoids and flavonoids. Environ Toxicol Pharmacol 11: 321-333

41. BORS W, MICHEL C (2002) Chemistry of the antioxidant effect of polyphenols. In: Alcohol and Wine in Health and Disease (Das DK, Ursini F, eds., New York Acad. Sci, New York, NY), Ann New York Acad Sci 957: 57-69

42. FERREIRA D, LI XC (2000) Oligomeric proanthocyanidins: naturally occurring O-heterocycles. Nat Prod Rep 17: 193-212
43. FELDMAN KS, LAWLOR MD, SAHASRABUDHE K (2000) Ellagitannin chemistry. Evolution of a threecomponent coupling strategy for the synthesis of the dimeric ellagitannin coriariin $A$ and a dimeric gallotannin analogue. J Org Chem 65: 8011-8019

44. KHANBABAEE K, VAN REE T (2001) Strategies for the synthesis of ellagitannins. Synthesis 11: 1585-1610

45. DOUGLAS CJ (1996) Phenylpropanoid metabolism and lignin biosynthesis: from weeds to trees. Trends Plant Sci 1: 171-178

46. ROS BARCELO A. (1997) Lignification in plant cell walls. Int Rev Cytol - Survey Cell Biol. 176: 87-132

47. BURLAR V, KWON M, DAVIN LB, LEWIS NG (2001) Dirigent proteins and dirigent sites in lignifying tissues. Phytochemistry 57: 883-897 